\title{
Cardiovascular Protective Effects of Centella asiatica and Its Triterpenes: A Review
}

Authors

Nur Nadia Mohd Razali ${ }^{1}$, Chin Theng $\mathbf{N g}^{2}$, Lai Yen Fong ${ }^{1}$

\section{Affiliations}

1 Department of Pre-clinical Sciences, Faculty of Medicine and Health Sciences, Universiti Tunku Abdul Rahman, Kajang, Selangor, Malaysia

2 Physiology Unit, Faculty of Medicine, AIMST University, Bedong, Kedah, Malaysia

Key words

Centella asiatica, Apiaceae, asiatic acid, asiaticoside, madecassic acid, madecassoside, cardiovascular protective effect

received April 1, 2019

revised August 9, 2019

accepted August 30, 2019

Bibliography

DOI https://doi.org/10.1055/a-1008-6138

Published online September 20, 2019 | Planta Med 2019; 85: 1203-1215 @ Georg Thieme Verlag KG Stuttgart · New York । ISSN 0032-0943

\section{Correspondence}

Assistant Professor Dr. Lai Yen Fong

Department of Pre-clinical Sciences, Faculty of Medicine and

Health Sciences, Universiti Tunku Abdul Rahman, Sungai Long Campus

Jalan Sungai Long, Bandar Sungai Long, 43000 Kajang,

Selangor, Malaysia

Phone: + 60133887270 , Fax: + 60390191959

fongly@utar.edu.my

\section{ABSTRACT}

Centella asiatica, a triterpene-rich medicinal herb, is traditionally used to treat various types of diseases including neurological, dermatological, and metabolic diseases. A few articles have previously reviewed a broad range of pharmacological activities of $C$. asiatica, but none of these reviews focuses on the use of $C$. asiatica in cardiovascular diseases. This review aims to summarize recent findings on protective effects of C. asiatica and its active constituents (asiatic acid, asiaticoside, madecassic acid, and madecassoside) in cardiovascular diseases. In addition, their beneficial effects on conditions associated with cardiovascular diseases were also reviewed. Articles were retrieved from electronic databases such as PubMed and Google Scholar using keywords "Centella asiatica," "asiatic acid," "asiaticoside," "madecassic acid," and "madecassoside." The articles published between 2004 and 2018 that are related to the aforementioned topics were selected. A few clinical studies published beyond this period were also included. The results showed that $C$. asiatica and its active compounds possess potential therapeutic effects in cardiovascular diseases and cardiovascular disease-related conditions, as evidenced by numerous in silico, in vitro, in vivo, and clinical studies. C. asiatica and its triterpenes have been reported to exhibit cardioprotective, anti-atherosclerotic, antihypertensive, antihyperlipidemic, antidiabetic, antioxidant, and anti-inflammatory activities. In conclusion, more clinical and pharmacokinetic studies are needed to support the use of $C$. asiatica and its triterpenes as therapeutic agents for cardiovascular diseases. Besides, elucidation of the molecular pathways modulated by $C$. asiatica and its active constituents will help to understand the mechanisms underlying the cardioprotective action of $C$. asiatica.

\section{Introduction}

Natural products have served as important sources of medication for thousands of years. As about 34\% of modern medicines are derived from natural products between 2000 to 2014, more attention has been focused in drug discovery from medicinal plants [1]. Centella asiatica (L.) Urban, a tropical medicinal plant belonging to the family Apiaceae, is widely distributed in many parts of the world especially in Asian countries such as India, China, Nepal, and other Southeast Asia countries including Malaysia and Indo- nesia [2]. The plant can also be found in Australia, South Africa, the United States, and Europe [2]. C. asiatica is known as pegaga in Malaysia, cairuçu-asiático in Brazil, or mandukparni in India, but is most popularly called as Gotu Kola or Indian pennywort in many countries $[3,4]$. C. asiatica is a creeper plant with long stalk that attains height up to $15 \mathrm{~cm}$. It has clustered and dented-blade leaves with sizes of $2-5 \mathrm{~cm}$. The plant can tolerate a wide range of conditions but is abundantly found in damp and swampy areas, as well as in sandy and clay soil $[3,5]$. 


\begin{tabular}{|c|c|}
\hline \multicolumn{2}{|c|}{ ABBREVIATIONS } \\
\hline $2 \mathrm{~K}-1 \mathrm{C}$ & 2-kidney one-clip \\
\hline ABTS & $\begin{array}{l}\text { 2,2'-azino-bis(3-ethylbenzothiazoline-6-sulfonic } \\
\text { acid) }\end{array}$ \\
\hline AMPK $\alpha$ & $\begin{array}{l}\text { adenosine monophosphate-activated protein } \\
\text { kinase } \alpha\end{array}$ \\
\hline ANP & atrial natriuretic peptide \\
\hline CAT & catalase \\
\hline cGMP & cyclic guanidine monophosphate \\
\hline cox & cyclooxygenase \\
\hline DPPH & 2,2-diphenyl-2-picrylhydrazyl hydrate \\
\hline NO & nitric oxide \\
\hline NOS & nitric oxide synthase \\
\hline ERK & extracellular signal-regulated kinase \\
\hline GPX & glutathione peroxidase \\
\hline GSH & glutathione \\
\hline GSK & glycogen synthase kinase \\
\hline HAEC & human aortic endothelial cells \\
\hline HDL & high-density lipoprotein \\
\hline HMG-CoA & 3-hydroxy-3-methyl-glutaryl coenzyme A \\
\hline HUVEC & human umbilical vein endothelial cells \\
\hline ICAM-1 & intracellular cell adhesion molecule-1 \\
\hline IL & interleukins \\
\hline JNK & c-Jun N-terminal kinase \\
\hline LDL & low-density lipoprotein \\
\hline L-NAME & $\mathrm{N} \omega$-Nitro-L-arginine methyl ester hydrochloride \\
\hline LPS & lipopolysaccharides \\
\hline MAPK & mitogen-activated protein kinases \\
\hline MDA & malondialdehyde \\
\hline mTOR & mammalian target of rapamycin \\
\hline NF- $\kappa \mathrm{B}$ & nuclear factor- $\kappa \mathrm{B}$ \\
\hline ox-LDL & oxidized low-density lipoprotein \\
\hline PECAM-1 & platelet endothelial cell adhesion molecule- 1 \\
\hline ROS & reactive oxygen species \\
\hline SOD & superoxide dismutase \\
\hline TAC & transverse aortic constriction \\
\hline TGF & transforming growth factor \\
\hline TTFCA & total triterpenic fraction of $C$. asiatica \\
\hline VCAM-1 & vascular cell adhesion molecule- 1 \\
\hline VLDL & very low-density lipoprotein \\
\hline
\end{tabular}

C. asiatica is known for its high nutritional contents and is a good source of dietary fibers [6]. In Malaysia, the plant is eaten raw, boiled, or cooked with coconut milk and usually served as a side dish with rice or as an appetizer. In countries such as India and Thailand, C. asiatica is consumed as juice, herbal tea, and tonic drink for health benefits. In Sri Lanka, it is a popular choice of nutritional breakfast, usually cooked as porridge [7]. As a medicinal plant, C. asiatica has also been traditionally used in Ayurvedic medicine and traditional Chinese medicine for treatment of various diseases. In traditional Ayuverdic medicine, C. asiatica has been used to enhance memory and to treat neurological diseases such as cognitive impairment and neurotoxicity [8]. The plant is also used to treat wounds, skin diseases such as leprosy, psoriasis and lupus, and some ailments including vomiting, diarrhea and fever $[9,10]$.

The major active constituents present in C. asiatica are triterpenes, namely asiatic acid, asiaticoside, madecassic acid, and madecassoside ( $\bullet$ Fig. $\mathbf{1}$ ) [11]. Standardized extracts of $C$. asiatica such as titrated extract of $C$. asiatica, TTFCA, and total triterpenic fraction are marketed under different trade names such as Madecassol, Centellase, and Blastoestimulina. The compositions of these highly purified extracts are the same in which $40 \%$ of the extracts are asiaticoside and the remaining $60 \%$ are a mixture of asiatic acid and madecassic acid $[12,13]$. Other standardized extracts of $C$. asiatica include ECa 233, which contains at least $80 \%$ asiaticoside and madecassoside [14] and Centellicum, which contains 35\% of triterpenes [15]. Besides triterpenes, C. asiatica was found to have other phenolic compounds such as flavonoids (quercetin and kaempferol), phytosterol (campesterol, sitosterol, and stigmasterol), gulonic acid, ferulic acid, and chlorogenic acid [16]. Nevertheless, the nutritional and medicinal values of this plant are mainly attributed to the presence of triterpenes [17].

For the past decades, a large number of studies have been conducted to reveal the therapeutic potential and mechanism of action of $C$. asiatica. Accumulating evidence suggested that $C$. asiatica exhibits wound healing [18], neuroprotective [19], antioxidant [20], and anti-inflammatory effects [21] in both in vitro and in vivo models. Over the past few years, researchers have shown increased interest in exploring the potential use of $C$. asiatica for the treatment of cardiovascular diseases. Several preclinical and clinical studies have investigated cardioprotective effects of C. asiatica using various types of $C$. asiatica extracts and its triterpenoids.

Cardiovascular disease continues to be the leading cause of death worldwide. The major types of cardiovascular diseases include ischemic heart disease, stroke, cardiomyopathy, cerebrovascular disease, and rheumatic heart disease. The World Health Organization statistics updated on May 2017 reported that an estimated 17.9 million people died from cardiovascular diseases in 2016, representing $31 \%$ of all global deaths [22]. On top of that, Department of Statistics Malaysia reported that ischemic heart disease had remained as the main cause of death in Malaysia from 2005 to 2017. In 2017, 13.9\% of all causes of death is ischemic heart disease followed by pneumonia, $12.7 \%$, and cerebrovascular disease, $7.1 \%$ [23]. The risk factors for cardiovascular diseases include smoking, obesity, hypertension, diabetes, hyperlipidemia, oxidative stress, and inflammation. These risk factors, present as a single factor or combination of different factors, are associated with the formation and development of fatty streaks and plaques in arteries, which subsequently increases the risk of cardiovascular diseases [24].

A number of reviews on the bioactivities of $C$. asiatica and its chemical constituents have been published previously $[4,12,25-$ 27]. These reviews focused either on neuroprotective and dermatological effects of $C$. asiatica or reviewed generally on its bioactivities. To date, there is no review article focuses on the cardiovascular protective effects of $C$. asiatica and its active constituents. Therefore, this review aims to provide an overview on pharmacological activities of $C$. asiatica and its active constituents evaluated using in vitro, in vivo, and clinical studies, with an emphasis on the 


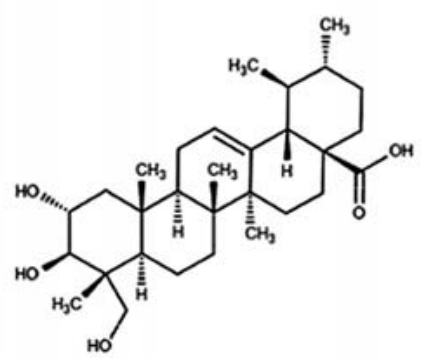

Asiatic acid

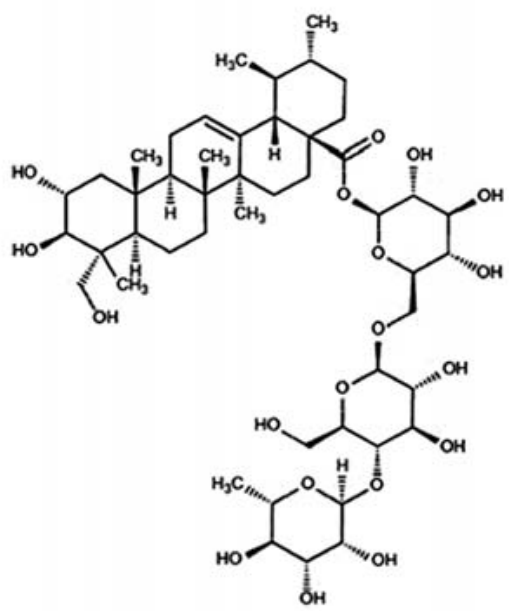

Asiaticoside

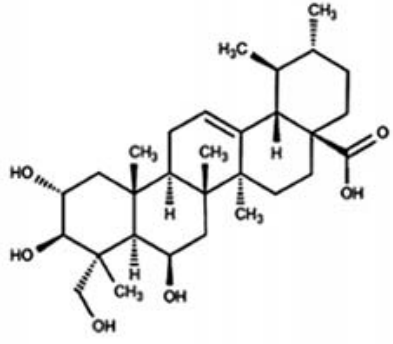

Madecassic acid

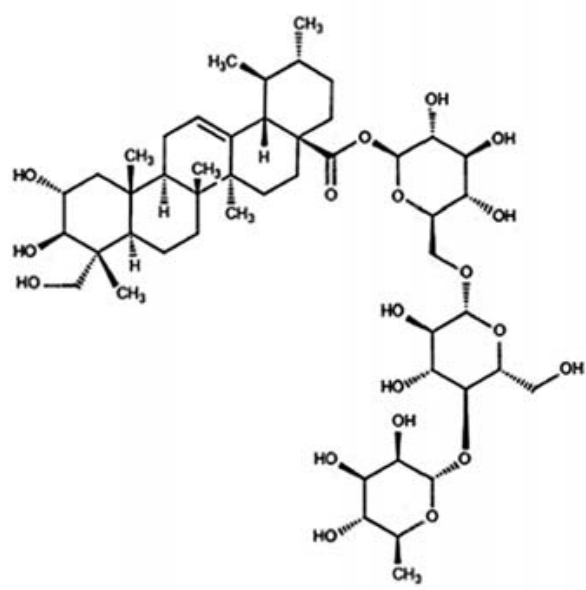

Madecassoside

- Fig. 1 Chemical structure of C. asiatica triterpenes.

protective effects of $C$. asiatica against cardiovascular diseases and cardiovascular related conditions such as atherosclerosis, hypertension, hyperlipidemia, hyperglycemia, oxidative stress, and inflammation.

\section{Cardioprotective Effects of $C$. asiatica and Its Triterpenes}

Cardiac failure occurs when the heart is incapable to pump sufficient blood to meet the body's demand. Myocardial ischemia and cardiomyopathy are the disease conditions that often lead to cardiac hypertrophy, a compensatory mechanism that eventually develops into cardiac failure and causing sudden death. Various mediators and multitude signaling pathways have been identified to play critical roles in the initiation and development of cardiac hypertrophy. Among the mediators involved are TNF- $\alpha$, IL, and TGF$\beta 1$, which bind to their respective membrane receptors and initiate a cascade of signal transduction pathways [28]. Subsequently, various kinases such as JNK, ERK, p38, mTOR, and GSK are activated by multiple upstream effectors $[28,29]$. These signaling events ultimately activate NF- $\kappa \mathrm{B}$, which in turn alters the expression of nuclear transcription factors, leading to pathological cardiac hypertrophy $[28,30]$.
The protective effect of $C$. asiatica extracts and its triterpenes against cardiac hypertrophy and myocardial ischemia have been demonstrated in several in vitro studies ( $\triangleright$ Table 1) [31-34]. These studies suggested that asiatic acid, one of the triterpenes of $C$. asiatica, exerts protective effects in cardiomyocytes by activating or deactivating key signaling pathways involved in the pathogenesis of cardiac hypertrophy and myocardial ischemia. An in vitro study on primary neonatal cardiomyocytes showed that asiatic acid attenuates cardiac hypertrophy and blocks TGF- $\beta 1$ mediated MAPK signaling events. The authors reported that $2.5-$ $30 \mu \mathrm{M}$ of asiatic acid significantly reduced TGF- $\beta 1$-induced increased cardiomyocyte surface area and ANP mRNA expression, concomitant with the inhibition of p38 and ERK phosphorylation, as well as NF- $\kappa B$ binding activity [34]. Other researchers have also demonstrated that asiatic acid attenuates myocardial hypertrophy stimulated by IL-1 $\beta$ [33]. Besides, $20 \mu \mathrm{M}$ of asiatic acid was found to inhibit hypertrophic responses induced by angiotensin II in cardiomyocytes by activating AMPK $\alpha$ and blocking mTOR and ERK pathways [32]. Using an in vitro model of ischemia-reperfusion injury, Huang et al. reported that asiatic acid protects H9c2 rat cardiomyocytes from oxygen-glucose deprivation/reoxygenation injury through an activation of the Akt/GSK-3 $\beta / \mathrm{HIF}-1 \alpha$ pathway [31]. Furthermore, the authors showed that $10 \mu \mathrm{M}$ of asiatic acid prevented cell apoptosis and reduced activities of caspase-3 
- Table 1 Cardioprotective effects of C. asiatica and its triterpenoids.

\begin{tabular}{|c|c|c|c|}
\hline Model & Extract/compound & Effect/mechanism & Reference \\
\hline \multirow[t]{4}{*}{ In vitro } & Asiatic acid & Prevents cardiomyocyte hypertrophic response induced by TGF- $\beta 1$ & [34] \\
\hline & Asiatic acid & Inhibits cardiomyocyte hypertrophic response stimulated by IL- $1 \beta$ & [33] \\
\hline & Asiatic acid & $\begin{array}{l}\text { Attenuates angiotensin II-induced hypertrophy of cardiac myocytes and accumulation } \\
\text { of collagen in cardiac fibroblasts }\end{array}$ & [32] \\
\hline & Asiatic acid & Protects H9c2 rat cardiomyocytes from oxygen-glucose deprivation/reoxygenation injury & [31] \\
\hline \multirow[t]{6}{*}{ In vivo } & Aqueous extract & Attenuates increased serum myocardial marker enzymes in cardiomyopathy rats & [35] \\
\hline & Asiatic acid & Prevents cardiac hypertrophy and fibrosis in pressure overload-induced mice & {$[32]$} \\
\hline & Asiatic acid & Prevents cardiac hypertrophy and dysfunction in pressure overload-induced mice & [34] \\
\hline & Asiatic acid & $\begin{array}{l}\text { Improves cardiac function and inhibits cardiac hypertrophy and left ventricular remodeling } \\
\text { following coronary artery ligation-induced myocardial infarction }\end{array}$ & [36] \\
\hline & Madecassoside & Decreases ischemia-reperfusion injury-induced myocardial infarction & [37] \\
\hline & Madecassoside & Reduces plasma TNF- $\alpha$ levels, prevents hypotension and tachycardia in LPS-induced rats & {$[38]$} \\
\hline
\end{tabular}

and caspase- 9 as well as Bax/Bcl-2 ratio in oxygen-glucose deprivation/reoxygenation-induced H9c2 cardiomyocytes. In addition, asiatic acid also attenuates mitochondrial dysfunction by suppressing ROS overproduction and intracellular $\mathrm{Ca}^{2+}$ levels as well as enhancing mitochondria membrane potential [31].

Cardioprotective effects of $C$. asiatica have also been demonstrated using in vivo models. A previous study showed that oral administration with $200 \mathrm{mg} / \mathrm{kg}$ of $C$. asiatica aqueous extract attenuated increased activities of cardiac marker enzymes such as lactate dehydrogenase, creatine phosphokinase, glutamate oxaloacetate transaminase, and glutamate pyruvate transaminase in adriamycin-induced rats [35]. Furthermore, the authors also reported that $C$. asiatica extract enhanced activities of antioxidant enzymes, including total reduced GSH, glutathione-S-transferase, GPX, and SOD, in the heart tissue of adriamycin-induced rats. These data imply that asiatic acid improves cardiac function and enhances antioxidant defense mechanisms of the cardiotoxic agents-treated rat myocardium.

In addition to the cardioprotective effects of $C$. asiatica extracts, triterpenes of $C$. asiatica have also been shown to possess beneficial effects in cardiac injury. Ma et al. reported that 10 and $30 \mathrm{mg} / \mathrm{kg}$ asiatic acid administered orally for $7 \mathrm{wk}$ prevented pressure overload-induced cardiac hypertrophy and fibrosis in mice through activation of AMPK $\alpha$ and inhibition of ERK and mTOR [32]. By using a pharmacological inhibitor of AMPK $\alpha$ and AMPK $\alpha$ knockout mice models, they also demonstrated that AMPK $\alpha$ inhibition ablates the cardioprotective effects of asiatic acid. A previous study demonstrated that oral administration of asiatic acid at daily doses of $100 \mathrm{mg} / \mathrm{kg}$ for $2 \mathrm{wk}$ attenuated cardiac hypertrophy and cardiac dysfunction in TAC-induced mice. Asiatic acid was also found to decrease expressions of ANP and TGF- $\beta 1$ in hypertrophic myocardium of the mice. In terms of molecular pathways, asiatic acid blocks p38 and ERK1/2 phosphorylation, as well as NF$\kappa \mathrm{B}$ activation in vivo [34]. Researchers also showed that oral administration of $25 \mathrm{mg} / \mathrm{kg}$ of asiatic acid improved cardiac dysfunction and alleviated left ventricular remodeling in rat myocardial infarction model, as evidenced by a marked reduction in cardiac hypertrophy and interstitial fibrosis in the infarct border zone
[36]. Furthermore, the authors also demonstrated that asiatic acid reduces inflammatory cytokine levels such as TGF- $\beta 1$ and TNF- $\alpha$ and downregulates NF- $K$ B levels as well as attenuates p38 MAPK and ERK1/2 phosphorylation [36]. In vivo experimental approaches also showed that 2-h reperfusion with $50 \mathrm{mg} / \mathrm{kg}$ of madecassoside protected against ischemia-reperfusion-injury-induced myocardial infarction in Wistar rats through reduction of lipid peroxidation, inflammatory and apoptotic markers [37]. Intragastric administration of $20 \mathrm{mg} / \mathrm{kg}$ of madecassoside for $5 \mathrm{~d}$ has also been reported to reduce elevated plasma TNF- $\alpha$ levels, delay the fall of mean arterial pressure and diminish tachycardia in LPS-stimulated rats [38]. On top of that, the authors also showed that madecassoside inhibits LPS-induced increased TNF$\alpha$ levels and NF- $\kappa$ B, ERK, and p38 MAPK activation in neonatal rat cardiomyocytes [38].

\section{Anti-Atherosclerotic Effects of C. asiatica and Its Triterpenes}

Atherosclerosis, an underlying pathology of coronary heart diseases, is a chronic inflammatory disease [39]. In the early stage of atherosclerosis, various types of pro-inflammatory mediators, including ox-LDL and cytokines, impair endothelial function, which in turn causes an increase in endothelial permeability and overexpression of cell adhesion molecules on the apical surface of endothelial cells. These subsequently cause a remarkable increase in adhesion and migration of leukocytes across the endothelium. Among all types of leukocytes, mononuclear monocytes play crucial roles in initiating the formation of atherosclerotic lesions. The adhered monocytes migrate into the intima and differentiate into macrophages that are capable to engulf and oxidize lipids. Accumulation of cytoplasmic lipids in these macrophages results in the formation of foam cells, which serve as a hallmark of early atherosclerotic lesion formation [40].

Antithrombotic effect of 10 active compounds isolated from C. asiatica was evaluated by subjecting blood collected from rat abdominal aorta to haemostatometry, in which platelet reactivity 
- Table 2 Anti-atherosclerotic effects of C. asiatica and its triterpenoids.

\begin{tabular}{|l|l|l|l|l|}
\hline Model & Extract/compound & Effect/mechanism & Reference \\
\hline Ex vivo & 3,5-di-O-caffeoylquinic acid & Shows antithrombotic and inhibitory effects on platelet reactivity & {$[41]$} \\
\hline Clinical study & $\begin{array}{l}\text { Standardized leaf extract in combina- } \\
\text { tion with pine bark extract }\end{array}$ & Stabilizes plaque density in carotid and femoral arteries & {$[42]$} \\
\cline { 2 - 4 } & Total triterpenic fraction & Prevents the progression of atherosclerotic plaques & {$[43,44]$} \\
\hline
\end{tabular}

- Table 3 Antihypertensive effects of $C$. asiatica and its triterpenoids.

\begin{tabular}{|c|c|c|c|}
\hline Model & Extract/compound & Effect/mechanism & Reference \\
\hline \multirow[t]{6}{*}{ In vivo } & Asiatic acid & Improves alteration of the hemodynamics in $2 \mathrm{~K}-1 \mathrm{C}$ hypertensive rats & {$[50]$} \\
\hline & Asiatic acid & Reduces blood pressure by improving NO bioavailability in L-NAME-induced hypertensive rats & [51] \\
\hline & Asiatic acid & $\begin{array}{l}\text { Improves hemodynamic abnormalities such as increased blood pressure, heart rate, and hind- } \\
\text { limb vascular resistance in high carbohydrate, high-fat-diet-induced metabolic syndrome rats }\end{array}$ & {$[52]$} \\
\hline & Asiatic acid & $\begin{array}{l}\text { Reduces blood pressure by decreasing renin angiotensin overactivity, sympathetic nerve } \\
\text { overactivity and improving vascular function in high-carbohydrate and high-fat-diet-induced } \\
\text { metabolic syndrome rats }\end{array}$ & [53] \\
\hline & Asiaticoside & Reduces systemic blood pressure in hypoxia-induced pulmonary hypertensive rat & [54] \\
\hline & Asiaticoside & $\begin{array}{l}\text { Inhibits raised blood pressure and improves impaired production of NO and cGMP in hypoxia- } \\
\text { induced pulmonary hypertensive rat }\end{array}$ & [55] \\
\hline \multirow{2}{*}{$\begin{array}{l}\text { Clinical } \\
\text { study }\end{array}$} & TTFCA & Decreases ankle edema by reducing capillary filtration rate & [56] \\
\hline & TTFCA & Improves microcirculation and capillary permeability in patients with venous hypertension & [57] \\
\hline
\end{tabular}

and dynamic blood coagulation were measured ex vivo ( $\bullet$ Table 2) [41]. Based on the findings from haemostatometry, Satake et al. reported that only 3,5-di-O-caffeoylquinic acid showed a potential antithrombotic effect. A previous clinical study has reported that $C$. asiatica supplemented with Pycnogenol (pine bark extract) stabilizes the plaque density in the carotid and femoral arteries of asymptomatic subjects by improving plaque echogenicity. The subjects were supplemented with Pycnogenol, at daily doses of $150 \mathrm{mg}$, and Centellicum (standardized C. asiatica leaf extract) at daily doses of $450 \mathrm{mg}$, for a duration of 6 mo [42]. Other clinical studies have also shown that administration of TTFCA supplemented with Pycnogenol reduces the progression of arterial plaque formation in asymptomatic patients, which is associated with a decrease in oxidative stress $[43,44]$.

\section{Antihypertensive Effects of $C$. asiatica and Its Triterpenes}

Hypertension is a condition of persistent elevation of systolic or diastolic blood pressure over a baseline level. According to hypertension clinical guidelines published by the American Heart Association in 2018, normal blood pressure level is defined as 119/ $79 \mathrm{mmHg}$ or below while stage 1 hypertension is now defined as a blood pressure level equivalent to or above $130 / 80 \mathrm{mmHg}$ [45]. The role of hypertension as one of the risk factors of cardiovascular diseases has been thoroughly investigated in the past decade and its association with cardiovascular diseases is now well established. A Framingham heart study conducted in 1961 suggested that elevated blood pressure increases the prevalence of coronary heart disease in men and women by 2.6 and 6 folds, respectively [46]. A meta-analysis showed that lowering blood pressure causes a significant reduction in the risk of cardiovascular diseases and mortality [47]. It is well accepted that mechanisms such as sympathetic nervous system hyperactivity, renin-angiotensin-aldosterone system activation, and endothelial dysfunction may result in impairment of NO production, which are involved in the pathogenesis of hypertension [48]. Increased oxidative stress has also been proposed as a mechanism that triggers endothelial dysfunction in hypertension [49].

Asiatic acid has been demonstrated to exhibit antihypertensive effects in $2 \mathrm{~K}-1 \mathrm{C}$ renovascular hypertensive rats, where intragastric administration of $30 \mathrm{mg} / \mathrm{kg} / \mathrm{d}$ of asiatic acid for $4 \mathrm{wk}$ normalized the increased mean arterial blood pressure and heart rate of the rats ( $\triangleright$ Table 3 ) [50]. They also reported that asiatic acid attenuates renin-angiotensin system activation, overproduction of oxidative stress markers including superoxide anion $\left(\mathrm{O}_{2}^{-}\right)$and MDA, elevated gp91 ${ }^{\text {phox }}$ and TNF- $\alpha$ levels, and NF- $\kappa$ B protein overexpression [50]. Another study showed that oral administration of asiatic acid at daily doses of $10-20 \mathrm{mg} / \mathrm{kg}$ for $2 \mathrm{wk}$ enhanced hemodynamic status and re-established vascular function in LNAME-induced hypertensive rats by increasing NO bioavailability [51]. Pakdeechote et al. reported that intragastric administration of asiatic acid for 3 wk restores metabolic and hemodynamic abnormalities in rats by ameliorating insulin resistance, dyslipidemia, and hypertension and also suppresses excessive release of oxidative stress markers and upregulated NOS expression [52]. In agreement with these findings, asiatic acid administered orally at 
- Table 4 Antihyperlipidemic effects of $C$. asiatica and its triterpenoids.

\begin{tabular}{|c|c|c|c|}
\hline Model & Extract/compound & Effect/mechanism & Reference \\
\hline \multirow[t]{6}{*}{ In vivo } & Water extract & $\begin{array}{l}\text { Enhances hepatic structure, reduces lipid accumulation in hepatocytes and } \\
\text { lowers serum lipid levels in high cholesterol-fed rats }\end{array}$ & {$[63]$} \\
\hline & Fraction of ethanol extract & $\begin{array}{l}\text { Reduces total cholesterol, triglyceride and LDL levels in hyperlipidemic mice } \\
\text { and golden hamsters }\end{array}$ & [64] \\
\hline & Methanol extract & Reduces serum triglyceride levels in streptozotocin-induced diabetic rats & [65] \\
\hline & $\begin{array}{l}\text { Ethanol extract of C. asiatica } \\
\text { in combination with F. nilgerrensis } \\
\text { ethanol extract }\end{array}$ & Reduces lipid profile in serum and fatty acid deposition in hyperlipidemic rats & [66] \\
\hline & Asiatic acid & $\begin{array}{l}\text { Improves plasma lipid profile, increases activities of lecithin cholesterol } \\
\text { acyltransferase and lipoprotein lipase and decreases HMG-CoA reductase } \\
\text { activity in streptozotocin-induced diabetic rats }\end{array}$ & [67] \\
\hline & Asiatic acid & $\begin{array}{l}\text { Improves plasma lipid profile and altered gene and protein expression } \\
\text { of lipid metabolism enzymes in high fat diet-fed rats }\end{array}$ & [68] \\
\hline In silico & Asiatic acid & Shows good interaction and affinity towards the HMG-CoA active site & {$[67]$} \\
\hline
\end{tabular}

daily doses of $20 \mathrm{mg} / \mathrm{kg}$ for $3 \mathrm{wk}$ has also been shown to improve hypertension and tachycardia, renin-angiotensin system activation, sympathetic nerve hyperactivity, and other metabolic parameters, including total cholesterol, blood glucose and insulin levels. In addition, asiatic acid also improves vascular function in rats [53].

Prophylactic effects of asiaticoside was demonstrated by Wang et al. where intragastric administration of asiaticoside at daily doses of $50 \mathrm{mg} / \mathrm{kg}$ for $4 \mathrm{wk}$ diminished elevated mean pulmonary artery pressure, cardiac hypertrophy and pulmonary vascular remodeling in hypoxia-induced pulmonary hypertension [54]. Using real-time quantitative polymerase chain reaction and western blotting, asiaticoside was found to decrease the expression of TGF- $\beta 1$, TGF- $\beta$ receptor, Smad2/3, and phosphorylated Smad2/3 in the lungs of hypoxic rats. In addition, these authors also demonstrated therapeutic effects of asiaticoside on hypoxia-induced pulmonary hypertension in rats. A recent study also reported that asiaticoside restores blood pressure, improves impaired NO production and cGMP secretion and suppresses increased plasma endothelin-1 levels in established pulmonary hypertension [55].

Venous hypertension causes an increase in blood flow and a reduction in veno-arteriolar reflex, leading to foot and ankle edema. Daily treatment with $90 \mathrm{mg}$ or $180 \mathrm{mg}$ of TTFCA for 4 wk was shown to decrease ankle edema by reducing capillary filtration rate in patients with venous hypertension compared to placebo [56]. Another study has shown that treatment with TTFCA at $180 \mathrm{mg}$ once daily for $2 \mathrm{wk}$ improved microcirculation and capillary permeability in patients with moderate and serious venous hypertension [57].

\section{Antihyperlipidemic Effects of $C$. asiatica and Its Triterpenes}

Hyperlipidemia is one of the major risk factors for cardiovascular diseases [58]. Apart from total plasma cholesterol and triglyceride levels, the level of lipoproteins such as chylomicrons, VLDL, LDL, and $\mathrm{HDL}$ is also a reflection of the amount of plasma lipids due to the fact that lipids are transported by lipoproteins in the blood. An elevated plasma cholesterol level, particularly due to increased LDL levels, has been linked to most of the pathological effects caused by hyperlipidemia. Effects of LDL on endothelial function has been reviewed in depth previously [59]. ox-LDL has also been shown to increase endothelin production, which causes abnormal coronary vasomotion [60]. On the other hand, HDL mediate reverse cholesterol transport, a mechanism by which excess cholesterol is removed from body cells and transported to the liver for elimination from the body. Hence, novel therapeutic approaches focusing on raising HDL-cholesterol levels are being intensively investigated in the past decade [61]. Currently, the primary target and first-line therapy for hyperlipidemia is lowering of plasma LDL cholesterol levels [62] using statins or inhibitors of HMG-CoA reductase, which is a rate-limiting enzyme in the cholesterol synthesis pathway.

There is evidence from several in vivo studies that demonstrates antihyperlipidemic properties of $C$. asiatica ( $\triangleright$ Table 4 ). Oral administration of $C$. asiatica leaf extract prevents lipid droplet accumulation in rat hepatocytes and reduces serum lipid levels in high cholesterol-fed rats [63]. Intragastric administration of a fraction of $C$. asiatica ethanol extract has also been found to improve serum lipid profiles of hyperlipidemic mice and golden hamsters, in addition to its capability of enhancing reverse cholesterol transport [64]. These findings are consistent with other study reporting that streptozotocin-induced diabetic rats treated with $C$. asiatica methanol extract showed a reduction of plasma triglyceride concentrations compared to diabetic rats that did not receive any treatment [65]. Moreover, combination of C. asiatica and Fragaria nilgerrensis (Rosaceae) ethanol extracts significantly decreased serum lipid profile, prevented hepatic fat deposition and reduced lipid peroxidation in high-fat diet-induced rats [66]. Ramachandran et al. provided convincing evidence that an oral administration of $20 \mathrm{mg} / \mathrm{kg}$ of asiatic acid had a beneficial effect in normalizing total cholesterol, triglyceride, LDL, VLDL, free fatty acid, and phospholipid levels in experimental animal models of diabetes [67]. The authors also reported that activities of lipid metabolizing enzymes such as lecithin cholesterol acyltransferase 
- Table 5 Antihyperglycemic effects of C. asiatica and its triterpenoids.

\begin{tabular}{|c|c|c|c|}
\hline Model & Extract/compound & Effect/mechanism & Reference \\
\hline \multirow[t]{5}{*}{ In vivo } & Ethanol extract & $\begin{array}{l}\text { Lowers fasting blood glucose levels, improves glucose tolerance, decreases intestinal } \\
\text { glucose absorption, and suppresses activities of carbohydrate-digesting enzymes in } \\
\text { streptozotocin-induced diabetic rats }\end{array}$ & [72] \\
\hline & Asiatic acid & Reduces blood glucose and insulin levels as well as islet fibrosis in Goto-Kakizaki rats & [73] \\
\hline & Asiatic acid & $\begin{array}{l}\text { Protects against diabetic nephropathy in rats via inhibition of oxidative stress and the } \\
\text { JNK signaling pathway }\end{array}$ & [74] \\
\hline & Asiatic acid & Normalizes plasma glucose and insulin levels in streptozotocin-induced diabetic rats & [67] \\
\hline & Asiatic acid & $\begin{array}{l}\text { Prevents increased activities of glucose-6-phosphatase and fructose-1,6-bisphospha- } \\
\text { tase of carbohydrate metabolism in streptozotocin-induced diabetic rats }\end{array}$ & [75] \\
\hline
\end{tabular}

and lipoprotein lipase were increased by asiatic acid, whereas activity of HMG-CoA reductase was decreased upon asiatic acid treatment. In rats fed with high fat diet, asiatic acid has been demonstrated to exert anti-obesity activity by lowering body weight gain, plasma lipid levels, and expression of lipid-metabolizing enzymes [68]. By using an in silico molecular docking study, asiatic acid was found to have a high affinity for the binding site of HMG-CoA reductase, suggesting that asiatic acid is a specific inhibitor of HMG-CoA reductase [67]. To date, among the 4 major triterpenoids derived from $C$. asiatica, only asiatic acid has been shown to possess lipid-lowering effects in several high fat diet-induced animal models. Therefore, future investigations should focus on assessing hypolipidemic activities of asiaticoside, madecassoside, and madecassic acid.

\section{Antidiabetic Effects of $C$. asiatica and Its Triterpenes}

Diabetes mellitus is a group of metabolic disorders characterized by chronic hyperglycemia resulting from abnormal blood glucose regulation. Patients with type 1 diabetes, as a result of insufficient insulin production due to destruction of the pancreatic islet cells, are at higher risks of developing cardiovascular diseases compared to nondiabetic patients [69]. In type 2 diabetes, insulin resistance occurs where the body cells respond poorly to insulin and this causes a persistent increase in blood glucose and insulin levels. Diabetes has been shown to associate with rapid progression of atherosclerosis, as evidenced in diabetic patients exhibiting a greater percent of atheroma volume and a smaller size of coronary artery lumen, compared to nondiabetic individuals [70]. In terms of pathogenesis of diabetes, numerous mechanisms have been proposed, of which vascular changes resulting from hyperglycemia play predominant roles. The roles of endothelial dysfunction, vascular inflammation, increased oxidative stress, arterial calcification, and hypercoagulability in pathophysiology of diabetes have been thoroughly discussed elsewhere [71].

A number of in vivo studies have demonstrated the antihyperglycemic activity of $C$. asiatica ( $\vee$ Table 5 ). Kabir et al. has reported that $C$. asiatica ethanol extract decreases intestinal glucose absorption in type 2 diabetic rats and reduces breakdown of carbohydrates through inhibition of $\alpha$-amylase and intestinal disaccha- ridase activities [72]. The authors also demonstrated that oral administration of $1000 \mathrm{mg} / \mathrm{kg}$ of C. asiatica ethanol extract for $28 \mathrm{~d}$ lowers fasting blood glucose levels and improves glucose tolerance in streptozotocin-induced type 2 diabetic rats, but the extract does not alter plasma insulin levels [72]. Furthermore, effects of $C$. asiatica on organ weights and food habits of the rats following chronic administration of $C$. asiatica extract have also been examined, where food intake, water intake and body weight of the rats were significantly decreased. This might be attributed to the high doses used in the study. In contrast to the findings reported by Kabir et al., a previous study found that asiatic acid lowers blood glucose and insulin levels as well as fibrosis of pancreatic islets in Goto-Kakizaki rats, which is a spontaneous type 2 diabetes animal model [73]. Wang's findings are also controversial to the study reported by Ramachandran et al., in which asiatic acid decreases glucose levels but increases insulin levels in diabetic rats [67]. Taken together, it is clear that $C$. asiatica and its active constituents differently alter plasma insulin levels. Hence, antihyperglycemic activity of $C$. asiatica may not correlate with regulation of plasma insulin concentration.

Moreover, a recent study showed that 10,20 , and $40 \mathrm{mg} / \mathrm{kg}$ of asiatic acid, administered via oral gavage for $8 \mathrm{wk}$, protected against diabetic nephropathy in rats via inhibition of oxidative stress and the JNK signaling pathway [74]. A previous study also reported that intragastric administration of asiatic acid suppresses not only elevated plasma glucose and glycosylated hemoglobin levels but also suppresses increased activities of carbohydrate-metabolizing enzymes such as glucose-6-phosphatase and fructose-1,6-bisphosphatase in diabetic rats [75].

\section{Antioxidant Effects of $C$. asiatica and Its Triterpenes}

Oxidative stress is one of the contributors for pathological diseases such as cancer, pulmonary diseases and cardiovascular diseases [76]. It occurs when there is an imbalance between ROS production and antioxidant systems [76]. ROS are by-products of cellular metabolism which are derived from oxygen molecules $\left(\mathrm{O}_{2}\right)$. The major types of ROS include NO, hydrogen peroxide $\left(\mathrm{H}_{2} \mathrm{O}_{2}\right)$, hydroxyl radicals $(\cdot \mathrm{OH})$, and $\mathrm{O}_{2}^{-}$[77]. In physiological conditions, antioxidant systems, which include enzymatic and nonen- 
- Table 6 Antioxidant effects of C. asiatica and its triterpenoids.

\begin{tabular}{|c|c|c|c|}
\hline Model & Extract/compound & Effect/mechanism & Reference \\
\hline \multirow[t]{7}{*}{ In vitro } & Aqueous extract & Scavenges DPPH free radicals & {$[80]$} \\
\hline & Water extract & $\begin{array}{l}\text { Scavenges free radicals such as DPPH, } \mathrm{ABTS}^{+}, \mathrm{H}_{2} \mathrm{O}_{2} \text {, and NO, elevates SOD and GSH } \\
\text { levels, and inhibits lipid peroxidation }\end{array}$ & [63] \\
\hline & Water infusion & Possesses DPPH scavenging activity and ability to reduce $\mathrm{Fe}^{3+}$ & {$[20]$} \\
\hline & Methanol extract & Possesses total antioxidant and DPPH scavenging activities & [79] \\
\hline & $\begin{array}{l}\text { Methanol extract and triterpene } \\
\text { fractions }\end{array}$ & $\begin{array}{l}\text { Shows radical scavenging activities in ABTS, DPPH, NO, peroxynitrite radical } \\
\text { absorbance capacity and oxygen radical absorbance capacity assays }\end{array}$ & {$[83]$} \\
\hline & $50 \%$ methanol: water extract & Inhibits auto-oxidation of $\beta$-carotene and linoleic acid & [81] \\
\hline & Madecassoside & Reduces $\mathrm{H}_{2} \mathrm{O}_{2}$-induced injury and apoptosis in human umbilical vein endothelial cells & {$[82]$} \\
\hline \multirow[t]{2}{*}{ In vivo } & $\begin{array}{l}\text { Methanol extract and triterpene } \\
\text { fractions }\end{array}$ & $\begin{array}{l}\text { Decreases elevated MDA levels, increases reduced GSH levels and SOD activity } \\
\text { in cerebral cortex and hippocampus of scopolamine-induced Wistar rats }\end{array}$ & [83] \\
\hline & Asiatic acid & $\begin{array}{l}\text { Reduces increased plasma } \mathrm{O}_{2}^{-} \text {, MDA, nitrate and nitrite levels as well as restores altered } \\
\text { eNOS expression in high carbohydrate, high fat diet-induced metabolic syndrome rats }\end{array}$ & {$[52]$} \\
\hline
\end{tabular}

zymatic antioxidants, can counterbalance oxidative stress by scavenging free radicals including ROS [78]. The major enzymatic antioxidants include SOD, CAT, and GPX while nonenzymatic antioxidants are vitamins $C$ and $E, G S H$, and $\beta$-carotene [76]. In the vascular wall, several enzymes such as NADPH oxidase, xanthine oxidase, uncoupled endothelial NOS (eNOS), and mitochondria respiratory chain catalyze the reduction of $\mathrm{O}_{2}$ to $\mathrm{O}_{2}{ }^{-} \cdot \mathrm{O}_{2}^{-}$can react with $\mathrm{NO}$ to form peroxynitrite that in turn affects vascular cells directly or it can be converted to $\mathrm{H}_{2} \mathrm{O}_{2}$ by SOD. CAT and GPx further convert $\mathrm{H}_{2} \mathrm{O}_{2}$ to $\mathrm{H}_{2} \mathrm{O}$ and $\mathrm{O}_{2}$. In the presence of iron, the extremely reactive $\cdot \mathrm{OH}$ can be spontaneously produced from $\mathrm{H}_{2} \mathrm{O}_{2}$.

A number of studies have shown that aqueous extract, methanol extract and water infusion of $C$. asiatica possess antioxidant effects ( $\triangleright$ Table 6 ) $[20,63,79,80]$. The aqueous extract of $C$. asiatica showed a potent DPPH scavenging activity with $\mathrm{IC}_{50}$ values of $31.25 \mu \mathrm{g} / \mathrm{mL}$ [80] and $9.62 \mu \mathrm{g} / \mathrm{mL}$ [63]. Moreover, it has been reported that C. asiatica tea infused at $100{ }^{\circ} \mathrm{C}$ for $10 \mathrm{~min}$ possessed highest antioxidant capacity [20]. On top of that, the total antioxidant activity of $C$. asiatica methanolic extract was found to be $623.78 \mu \mathrm{mol}$ of ascorbic acid/g of sample and the $\mathrm{IC}_{50}$ values assessed using DPPH assay was $19.89 \mathrm{mg} / \mathrm{mL}$ [79]. A previous study showed that $50 \%$ methanol: water extract of C. asiatica exhibits antioxidant activity with a total phenolic content of $23.1 \mathrm{mg} / \mathrm{g}$ [81]. C. asiatica aqueous extract also inhibits lipid peroxidation and the increased SOD and GSH levels [63]. Bian et al. also showed that madecassoside reduces lipid peroxidation and apoptosis via inhibition of caspase-3 and p38 MAPK activation [82].

A recent study showed that the highest antioxidant activity was exhibited by methanol extract of $C$. asiatica, followed by triterpene-free fraction of $C$. asiatica and then triterpene-enriched fraction of $C$. asiatica [83]. The authors used several biochemical antioxidant assays include ABTS, DPPH, NO radical scavenging assays, peroxynitrite radical absorbance capacity, and oxygen radical absorbance capacity assays. In addition, they also investigated in vivo antioxidant capability of $C$. asiatica methanol extract using male Wistar rats. Oxidative stress parameters such as lipid peroxidation estimation, GSH levels, and SOD activity in the brain homogenate were measured. The in vivo antioxidant activities of $C$. asiatica were corresponded to the in vitro data obtained from the biochemical antioxidant assays [83]. Furthermore, a previous study also showed that asiatic acid reduces oxidative stress markers including $\mathrm{O}_{2}{ }^{-}$production, plasma $\mathrm{NO}$ metabolites, and upregulated iNOS/eNOS protein expression in high-carbohydrate, high-fat diet-induced metabolic syndrome rats [52].

\section{Anti-Inflammatory Effects of C. asiatica and Its Triterpenes}

Inflammation plays an important role in the pathogenesis of cardiovascular diseases. Hence, treatments targeting inflammatory events may be a promising intervention to attenuate the development of cardiovascular diseases [84]. Pro-inflammatory stimuli including cytokines (IL and TNF- $\alpha$ ) and endotoxin (LPS) bind to their respective membrane receptors and stimulate the release or synthesis of many pro-inflammatory mediators such as prostaglandins, COX, nitric oxide and inducible NOS (iNOS). COX are key enzymes that catalyze the synthesis of prostaglandins from arachidonic acid. COX-1 is constitutively expressed in many cell types while COX-2 expression is highly inducible in response to pro-inflammatory stimuli. It has been reported that LPS modulates the inflammatory responses by recruiting myeloid differentiation primary response protein 88 at the plasma membrane and causing a subsequent activation of several signaling cascades such as the p38, ERK, and JNK pathways [85]. Besides, NF- $K B$ is a key player in the inflammatory response, and upon activation, NF- $\kappa$ B upregulates transcription of a broad range of pro-inflammatory genes, which in turn results in excessive production of various pro-inflammatory mediators.

Anti-inflammatory activities of $C$. asiatica and its bioactive constituents, as well as the underlying mechanisms involved, have been elucidated in numerous preclinical studies ( $\triangleright$ Table 7 ). In vivo studies have shown that methanol and ethanol extracts of C. asiatica reduce paw edema volume of rats induced by carra- 
- Table 7 Anti-inflammatory effects of C. asiatica and its triterpenoids.

\begin{tabular}{|c|c|c|c|}
\hline Model & Extract/compound & Effect/mechanism & Reference \\
\hline \multirow[t]{5}{*}{ In vivo } & Aqueous and ethanol extracts & Reduces edema volume in carrageenan-induced paw edema model in rats & [86] \\
\hline & Methanol extract & Attenuates carrageenan-induced paw edema in rats & [87] \\
\hline & Asiatic acid & $\begin{array}{l}\text { Decreases levels of inflammatory markers such as NO, TNF- } \alpha \text {, IL- } 1 \beta \text {, iNOS, COX-2, } \\
\text { and NF- } k B \text { in carrageenan-induced paw edema model in mice }\end{array}$ & {$[88]$} \\
\hline & Asiatic acid & $\begin{array}{l}\text { Decreases TNF- } \alpha \text { production and iNOS expression in high carbohydrate, high fat } \\
\text { diet-induced metabolic syndrome rats }\end{array}$ & [52] \\
\hline & Asiatic acid & $\begin{array}{l}\text { Prevents cisplatin-induced acute kidney injury by suppressing production of } \\
\text { pro-inflammatory cytokines and deactivating NF- } \mathrm{B} B\end{array}$ & [89] \\
\hline
\end{tabular}

- Table 8 Effects of C. asiatica and its triterpenoids on pro-inflammatory mediators.

\begin{tabular}{|c|c|c|c|}
\hline Model & Extract/compound & Effect/mechanism & Reference \\
\hline \multirow[t]{10}{*}{ In vitro } & Freeze-dried extract & Reduces monocyte adhesion to HUVEC and protein expression of VCAM-1 and ICAM-1 & {$[97]$} \\
\hline & Asiatic acid & $\begin{array}{l}\text { Suppresses increased expression of soluble VCAM-1, ICAM-1, PECAM-1, and E-selectin } \\
\text { in TNF- } \alpha \text {-induced HAEC }\end{array}$ & [99] \\
\hline & Asiatic acid & $\begin{array}{l}\text { Protects endothelial barrier function by preserving adherens junctions and preventing } \\
\text { tight junction redistribution in TNF- } \alpha \text {-induced HAEC }\end{array}$ & {$[100]$} \\
\hline & Asiatic acid & $\begin{array}{l}\text { Inhibits production of NO, PGE }, \text { IL-6, IL- } 1 \beta \text {, TNF- } \alpha \text { and suppresses iNOS and COX-2 } \\
\text { expressions as well as NF-KB activation in LPS-induced RAW264.7 cells }\end{array}$ & [103] \\
\hline & Asiaticoside & $\begin{array}{l}\text { Attenuates endothelial hyperpermeability and F-actin rearrangement in TNF- } \alpha \text {-induced } \\
\text { HAEC }\end{array}$ & {$[98]$} \\
\hline & Asiaticoside & $\begin{array}{l}\text { Inhibits endothelial hyperpermeability and increased adhesion molecule expressions } \\
\text { in ox-LDL-induced HUVEC }\end{array}$ & [101] \\
\hline & Asiaticoside G & Decreases NO and TNF- $\alpha$ secretion in LPS-induced RAW264.7 cells & {$[102]$} \\
\hline & Madecassic acid & $\begin{array}{l}\text { Attenuates elevated NO, PGE } 2 \text {, TNF- } \alpha, \mathrm{IL}-1 \beta \text {, and IL- } 6 \text { levels, suppresses increased iNOS and } \\
\text { COX- } 2 \text { expressions and downregulates NF- } \kappa \text { B activation in LPS-induced RAW264.7 cells }\end{array}$ & {$[104]$} \\
\hline & Madecassoside & Inhibits elevated NO, PGE 2 , TNF- $\alpha$, IL-1 $\beta$, and IL-6 levels in LPS-induced RAW264.7 cells & {$[104]$} \\
\hline & Madecassoside & $\begin{array}{l}\text { Inhibits TNF- } \alpha \text { production, NF- } \kappa \text { B activation and phosphorylation of ERK1/2 and p38 in } \\
\text { LPS-stimulated neonatal rat cardiomyocytes }\end{array}$ & [38] \\
\hline
\end{tabular}

geenan $[86,87]$. Huang et al. also showed that intraperitoneal injection of asiatic acid in the hind paw of mice decreases serum NO, TNF- $\alpha$ and IL- $1 \beta$ levels, MDA level, and iNOS, COX-2, and NF- $\kappa$ B expression in a mouse paw edema model [88]. A recent study reported that the protective effects of asiatic acid against cisplatininduced kidney injury is attributed to its anti-inflammatory and anti-apoptotic actions, where intraperitoneal administration of $50 \mathrm{mg} / \mathrm{kg}$ and $100 \mathrm{mg} / \mathrm{kg}$ of asiatic acid improved renal functions, reduced number of apoptotic cells, inhibited mRNA expressions of proinflammatory cytokines including TNF- $\alpha$ and IL- $1 \beta$, and suppressed NF- $\kappa \mathrm{B}$ activation in $\mathrm{C} 57 \mathrm{BL} / 6$ mice. The authors proposed that the anti-inflammatory effects exerted by asiatic acid may be partially associated with Smad-7 upregulation [89].
Inhibitory Effects of $C$. asiatica and Its Triterpenoids on Pro-Inflammatory
Mediators

Several studies have been performed on cultured cell lines to evaluate effects of $C$. asiatica and its triterpenoids on cellular events of inflammation induced by TNF- $\alpha$, ox-LDL, and LPS ( $\bullet$ Table 8 ). TNF$\alpha$, a pro-inflammatory cytokine with pleiotropic roles, is released by many cell types such as macrophages, endothelial cells, fibroblasts, and cardiomyocytes during inflammation. Given its major role in the regulation of inflammatory responses, TNF- $\alpha$ is implicated in many chronic inflammatory diseases such as rheumatoid arthritis, inflammatory bowel disease, and atherosclerosis. In ApoE-knockout mice, abrogation of TNF- $\alpha$ production attenuates the development of atherosclerotic lesions $[90,91]$. TNF- $\alpha$ has been shown to increase expression of ICAM-1, VCAM-1, and monocyte chemoattractant protein-1 (MCP-1) in the aorta of ApoE-knockout mice as well as macrophage uptake of ox-LDL [92]. Other than these early atherogenic events, TNF- $\alpha$ has also 
been demonstrated to trigger the formation of advanced atherosclerotic plaques [93], which implies the crucial role of this cytokine in the late stage of atherogenesis.

One of the early atherogenic events is oxidization of $L D L$ in the subendothelial space, which subsequently activates endothelial cells by upregulating expression of cell adhesion molecules and increasing monocyte adhesion and migration [94]. Monocytes migrate into the intima layer of the endothelium and differentiate into macrophages, which in turn engulf ox-LDL and cell debris, and ultimately transform into lipid-laden foam cells. ox-LDL acts by binding to its major receptor, lectin-like ox-LDL receptor-1 (LOX-1), which is highly expressed in atherosclerosis, hypertension, diabetes, and heart failure [95].

LPS is a crucial membrane component of Gram-negative bacteria, which provides structural integrity and contributes to the activity of bacterial endotoxin. Mammalian monocytes or macrophages are able to detect Gram-negative infection rapidly by recognizing LPS via Toll-like receptors. Upon binding with the receptors, LPS elicits a strong host inflammatory response that involves the secretion of a wide variety of pro-inflammatory mediators such as TNF- $\alpha, \mathrm{IL}-1 \beta$, and IL-6, and upregulation of expression of enzymes including iNOS and COX-2. LPS also increases ICAM-1 expression via enhancement of RhoA activity and activation of p38 and NF- $k$ B [96].

The beneficial effects of $C$. asiatica and its bioactive constituents in TNF- $\alpha$ - and ox-LDL-induced endothelial activation have been reported ( $\wedge$ Table $\mathbf{8}$ ). In a previous study, C. asiatica freezedried extract at a dosage of $25 \mu \mathrm{g} / \mathrm{mL}$ significantly reduced the protein expression of total and membrane VCAM- 1 and ICAM-1, in both normal and gestational diabetic HUVEC stimulated with TNF- $\alpha$, and this was associated with inhibition of p44/42 MAPK and NF-KB pathways. In addition, $25 \mu \mathrm{g} / \mathrm{mL}$ of C. asiatica freezedried extract also suppressed increased $U 937$ monocyte adhesion elicited by TNF- $\alpha$. Interestingly, a combination of $10 \mu \mathrm{g} / \mathrm{mL}$ of C. asiatica extract and $0.1 \mathrm{mM}$ of lipoic acid showed enhanced inhibitory effects, compared to C. asiatica extract alone [97]. Fong et al. demonstrated that $25 \mu \mathrm{M}$ and $50 \mu \mathrm{M}$ of asiaticoside significantly attenuated both TNF- $\alpha$-induced F-actin redistribution and increased permeability of HAEC, as evidenced by the data obtained from immunofluorescent staining and fluorescein isothiocyanate-dextran in vitro vascular permeability assay [98]. Following the use of an actin-depolymerizing agent, the authors proposed that the barrier protective effect of asiaticoside does not act through stabilization of F-actin filaments.

Moreover, asiatic acid also attenuates TNF- $\alpha$-stimulated HAEC activation by suppressing endothelial hyperpermeability and increased expression of soluble VCAM-1, ICAM-1, PECAM-1, and Eselectin [99]. A further mechanistic study on asiatic acid revealed that its barrier protective effect is associated with stabilization of F-actin and diphospho-myosin light chain, preservation of VE-cadherin and $\beta$-catenin organization, and prevention of tight junction disassembly [100]. Consistent with these findings, a similar study reported by jing et al. also showed that asiaticoside protects against endothelial hyperpermeability and inhibits increased expression of adhesion molecules in HUVEC [101].

Previous in vitro studies have also shown that triterpenes of C. asiatica attenuate release of inflammatory markers elicited by
LPS in several cell lines [38, 102-104]. Inhibition of iNOS, COX-2, IL-6, IL-1 $\beta$, and TNF- $\alpha$ expressions by asiatic acid in LPS-induced RAW 264.7 cells might be associated with a downregulation of NF- $\kappa$ B activation, and the latter is associated with an abrogation of $I_{\kappa} \mathrm{B}-\alpha$ degradation and suppression of nuclear p65 and p50 protein levels [103]. Besides, asiaticoside $G$ has been reported to decrease NO and TNF- $\alpha$ production in LPS-stimulated RAW 264.7 cells [102]. Furthermore, madecassic acid was found to inhibit iNOS, COX-2, TNF- $\alpha$, IL- $1 \beta$, and IL- 6 via the suppression of NF- $\kappa \mathrm{B}$ activation [104] and madecassoside has been reported to attenuate TNF- $\alpha$ production through inhibition of ERK1/2, p38 MAPK and NF- $K B$ pathways in LPS-stimulated neonatal rat cardiomyocytes [38].

\section{Conclusion}

C. asiatica is a useful medicinal plant with many potential pharmacological activities. Accumulating evidence from in vivo and clinical studies suggested that $C$. asiatica protects against cardiovascular diseases and their related conditions. The mechanisms underlying the cardiovascular protective effects of $C$. asiatica and its triterpenoids have also been revealed using in vitro and in silico models. Various extracts and compounds isolated from C. asiatica have been demonstrated to reduce the occurrence of cardiac hypertrophy, myocardial ischemia, atherosclerosis, hypertension, hyperlipidemia, hyperglycemia, diabetes, oxidative stress, and inflammation. The most widely studied extracts of $C$. asiatica for cardiovascular diseases are aqueous and alcoholic extracts. Among the triterpenes of $C$. asiatica, asiatic acid is the most extensively studied compound followed by asiaticoside and madecassoside. Madecassic acid, however, is the least reported triterpenoid, despite the fact that its therapeutic effects have been reported in a few studies. Therefore, pharmacological activity of madecassic acid should be investigated in detail in the future. While some studies have elucidated the molecular mechanisms underlying the cardiovascular protective effects of $C$. asiatica, more clinical and pharmacokinetic studies are still needed to justify the use of $C$. asiatica and its triterpenes as a therapeutic agent.

\section{Methodology}

A comprehensive literature search was performed for articles published between 1986 and August 2018. The information was retrieved from electronic databases such as PubMed, Google Scholar, ClinicalKey, Science Direct, Springer, and EBSCOhost. Search keywords used were "Centella asiatica", "asiatic acid", "madecassic acid”, "asiaticoside”, or "madecassoside". The articles published from 2004 to 2018 were screened, of which articles that reported protective effects of both $C$. asiatica and its active constituents against cardiovascular diseases and conditions leading to these diseases were selected and reviewed thoroughly. A few clinical studies published beyond this period were also included. Original articles and review articles published as full paper, but not abstract, were included in the selection. Review articles on other areas, such as neurology and dermatology, and not written in English were excluded. 


\section{Acknowledgements}

This work was supported by Universiti Tunku Abdul Rahman (Project number: IPSR/RMC/UTARRF/2017-C1/F01) and Ministry of Education, Malaysia (Project number: FRGS/1/2018/SKK06/UTAR/02/7).

\section{Conflict of Interest}

The authors declare that they have no conflict of interest.

\section{References}

[1] Newman DJ, Cragg GM. Natural products as sources of new drugs from 1981 to 2014. J Nat Prod 2016; 79: 629-661

[2] CABI. Centella asiatica [original text by Chris Parker]. In: Parker C. Invasive Species Compendium. Available at https://www.cabi.org/isc/datasheet/ 12048. Accessed September 13, 2019

[3] Chandrika UG, Prasad Kumarab PA. Gotu Kola (Centella asiatica): nutritional properties and plausible health benefits. Adv Food Nutr Res 2015; 76: 125-157

[4] Gohil KJ, Patel JA, Gajjar AK. Pharmacological review on Centella asiatica: a potential herbal cure-all. Indian J Pharm Sci 2010; 72: 546-556

[5] Joshi K, Chaturvedi P. Therapeutic efficiency of Centella asiatica (L.) Urb. An underutilized green leafy vegetable: an overview. Int J Pharma Bio Sci 2013; 4: 135-149

[6] Tee ES, Mohd Idris N, Mohd Nasir A, Khatijah I. Nutrient Composition of Malaysian Food. In: Tee ES, Mohd Idris N, Mohd Nasir A, Khatijah I. Malaysian Food Composition Database Programme. 4th ed. Kuala Lumpur: Institute of Medical Research; 1997: 16

[7] Cox DN, Rajasuriya SV, Soysa PE, Gladwin J, Ashworth A. Problems encountered in the community-based production of leaf concentrate as a supplement for pre-school children in Sri Lanka. Int J Food Sci Nutr 1993; 44: $123-132$

[8] Shinomol GK, Muralidhara, Bharath MM. Exploring the role of "Brahmi" (Bacopa monnieri and Centella asiatica) in brain function and therapy. Recent Pat Endocr Metab Immune Drug Discov 2011; 5: 33-49

[9] Hamidpour R, Hamidpour S, Hamidpour M, Zarabi M, Sohraby M, Hamidpour R. Medicinal property of Gotu kola (Centella asiatica) from the selection of traditional applications to the novel phytotherapy. Arch Cancer Res 2015; 3: 1-7

[10] Saini S, Dhiman A, Nanda S. Traditional indian medicinal plants with potential wound healing activity: a review. Int J Pharm Sci Res 2016; 7: 1809-1819

[11] Singh B, Rastogi R. A reinvestigation of the triterpenes of Centella asiatica. Phytochem 1969; 8: 917-921

[12] Bylka W, Znajdek-Awizen P, Studzinska-Sroka E, Danczak-Pazdrowska A, Brzezinska M. Centella asiatica in dermatology: an overview. Phytother Res 2014; 28: 1117-1124

[13] James JT, Dubery IA. Pentacyclic triterpenoids from the medicinal herb, Centella asiatica (L.) Urban. Molecules 2009; 14: 3922-3941

[14] Anukunwithaya T, Tantisira MH, Tantisira B, Khemawoot P. Pharmacokinetics of a standardized extract of Centella asiatica ECa 233 in rats. Planta Med 2017; 83: 710-717

[15] Cotellese R, Hu S, Belcaro G, Ledda A, Feragalli B, Dugall M, Hosoi M, Ippolito E. Centella asiatica (Centellicum ${ }^{\circledR}$ ) facilitates the regular healing of surgical scars in subjects at high risk of keloids. Minerva Chir 2018; 73 : 151-156

[16] Srivastava R, Shukla YN, Kumar S. Chemistry and pharmacology of Centella asiatica: a review. J Med Arom Plant Sci 1997; 19: 1049-1056
[17] Hashim P, Sidek H, Helan MH, Sabery A, Palanisamy UD, Ilham M. Triterpene composition and bioactivities of Centella asiatica. Molecules 2011; 16: $1310-1322$

[18] Sawatdee S, Choochuay K, Chanthorn W, Srichana T. Evaluation of the topical spray containing Centella asiatica extract and its efficacy on excision wounds in rats. Acta Pharm 2016; 66: 233-244

[19] Gray NE, Zweig JA, Matthews DG, Caruso M, Quinn JF, Soumyanath A. Centella asiatica attenuates mitochondrial dysfunction and oxidative stress in $A \beta$-exposed hippocampal neurons. Oxid Med Cell Longev 2017; 2017: 7023091

[20] Ariffin F, Heong Chew S, Bhupinder K, Karim AA, Huda N. Antioxidant capacity and phenolic composition of fermented Centella asiatica herbal teas. J Sci Food Agric 2011; 91: 2731-2739

[21] Cao SY, Wang W, Nan FF, Liu YN, Wei SY, Li FF, Chen L. Asiatic acid inhibits LPS-induced inflammatory response in endometrial epithelial cells. Microb Pathog 2018; 116: 195-199

[22] World Health Organization. Cardiovascular diseases (CVDs) fact sheet. Available at https://www.who.int/en/news-room/fact-sheets/detail/cardiovascular-diseases-(cvds). Accessed January 3, 2019

[23] Department of Statistics Malaysia. Statistics on Causes of Death, Malaysia, 2018. Available at https://www.dosm.gov.my/v1/index.php?r= column/pdfPrev\&id=aWg2VjJkZHhYcDdEM3JQSGloeTVIZz09. Accessed December 3, 2018

[24] McMahan CA, Gidding SS, McGill HC jr. Coronary heart disease risk factors and atherosclerosis in young people. J Clin Lipidol 2008; 2: 118-126

[25] Farooqui AA, Farooqui T, Madan A, Ong JH, Ong WY. Ayurvedic medicine for the treatment of dementia: mechanistic aspects. Evid Based Complement Alternat Med 2018; 2018: 2481076

[26] Lv ], Sharma A, Zhang T, Wu Y, Ding X. Pharmacological review on asiatic acid and its derivatives: a potential compound. SLAS Technol 2018; 23 : $111-127$

[27] Lokanathan Y, Omar N, Ahmad Puzi NN, Saim A, Hj Idrus R. Recent updates in neuroprotective and neuroregenerative potential of Centella asiatica. Malays J Med Sci 2016; 23: 4-14

[28] Heineke J, Molkentin JD. Regulation of cardiac hypertrophy by intracellular signalling pathways. Nat Rev Mol Cell Biol 2006; 7: 589-600

[29] Tham YK, Bernardo BC, Ooi JY, Weeks KL, McMullen JR. Pathophysiology of cardiac hypertrophy and heart failure: signaling pathways and novel therapeutic targets. Arch Toxicol 2015; 89: 1401-1438

[30] Huang Y, Wu D, Zhang X, Jiang M, Hu C, Lin J, Tang J, Wu L. Cardiac-specific Traf2 overexpression enhances cardiac hypertrophy through activating AKT/GSK3 $\beta$ signaling. Gene 2014; 536: 225-231

[31] Huang X, Zuo L, Lv Y, Chen C, Yang Y, Xin H, Li Y, Qian Y. Asiatic acid attenuates myocardial ischemia/reperfusion injury via Akt/GSK-3 $\beta / \mathrm{HIF}-1 \alpha$ signaling in rat H9c2 cardiomyocytes. Molecules 2016; 21: pii: E1248

[32] Ma ZG, Dai J, Wei WY, Zhang WB, Xu SC, Liao HH, Yang Z, Tang QZ. Asiatic acid protects against cardiac hypertrophy through activating AMPK $\alpha$ signalling pathway. Int J Biol Sci 2016; 12: 861-871

[33] Xu X, Si L, Xu J, Yi C, Wang F, Gu W, Zhang Y, Wang X. Asiatic acid inhibits cardiac hypertrophy by blocking interleukin- $1 \beta$-activated nuclear factor$\kappa \mathrm{B}$ signaling in vitro and in vivo. J Thorac Dis 2015; 7: 1787-1797

[34] Si L, Xu J, Yi C, Xu X, Wang F, Gu W, Zhang Y, Wang X. Asiatic acid attenuates cardiac hypertrophy by blocking transforming growth factor- $\beta 1$ mediated hypertrophic signaling in vitro and in vivo. Int ] Mol Med 2014; 34: 499-506

[35] Gnanapragasam A, Ebenezar KK, Sathish V, Govindaraju P, Devaki T. Pro tective effect of Centella asiatica on antioxidant tissue defense system against adriamycin induced cardiomyopathy in rats. Life Sci 2004; 76: 585-597

[36] Huo L, Shi W, Chong L, Wang J, Zhang K, Li Y. Asiatic acid inhibits left ventricular remodeling and improves cardiac function in a rat model of myocardial infarction. Exp Ther Med 2016; 11: 57-64 
[37] Bian GX, Li GG, Yang Y, Liu RT, Ren JP, Wen LQ, Guo SM, Lu Q]. Madecassoside reduces ischemia-reperfusion injury on regional ischemia induced heart infarction in rat. Biol Pharm Bull 2008; 31: 458-463

[38] Cao W, Li XQ, Zhang XN, Hou Y, Zeng AG, Xie YH, Wang SW. Madecassoside suppresses LPS-induced TNF- $\alpha$ production in cardiomyocytes through inhibition of ERK, p38, and NF-KB activity. Int Immunopharmacol 2010; 10: 723-729

[39] Shrivastava AK, Singh HV, Raizada A, Singh SK. C-reactive protein, inflammation and coronary heart disease. Egypt Heart ] 2015; 67: 89-97

[40] Kunjathoor VV, Febbraio M, Podrez EA, Moore KJ, Andersson L, Koehn S, Rhee JS, Silverstein R, Hoff HF, Freeman MW. Scavenger receptors class A-I/II and CD36 are the principal receptors responsible for the uptake of modified low density lipoprotein leading to lipid loading in macrophages. J Biol Chem 2002; 277: 49982-49988

[41] Satake T, Kamiya K, An Y, Oishi Nee Taka T, Yamamoto J. The anti-thrombotic active constituents from Centella asiatica. Biol Pharm Bull 2007; 30: 935-940

[42] Belcaro G, Cornelli U. Variations in echogenicity in carotid and femoral atherosclerotic plaques with Pycnogenol + Centella asiatica supplementation. Int J Angiol 2017; 26: 95-101

[43] Belcaro G, Dugall M, Hosoi M, Ippolito E, Cesarone M, Luzzi R, Cornelli U, Ledda A. Pycnogenol ${ }^{\circledR}$ and Centella asiatica for asymptomatic atherosclerosis progression. Int Angiol 2014; 33: 20-26

[44] Belcaro G, Ippolito E, Dugall M, Hosoi M, Cornelli U, Ledda A, Scoccianti M, Steigerwalt RD, Cesarone MR, Pellegrini L, Luzzi R, Corsi M. Pycnogenol ${ }^{\circledR}$ and Centella asiatica in the management of asymptomatic atherosclerosis progression. Int Angiol 2015; 34: 150-157

[45] Whelton PK, Carey RM, Aronow WS, Casey DE jr., Collins KJ, Dennison Himmelfarb C, DePalma SM, Gidding S, Jamerson KA, Jones DW, MacLaughlin EJ, Muntner P, Ovbiagele B, Smith SC jr., Spencer CC, Stafford RS, Taler SJ, Thomas RJ, Williams KA sr., Williamson JD, Wright JT jr. 2017 ACC/AHA/AAPA/ABC/ACPM/AGS/APhA/ASH/ASPC/NMA/ PCNA guideline for the prevention, detection, evaluation, and management of high blood pressure in adults: executive summary: a report of the American College of Cardiology/American Heart Association task force on clinical practice guidelines. Hypertension 2018; 71: 1269-1324

[46] Kannel WB, Dawber TR, Kagan A, Revotskie N, Stokes ] 3rd. Factors of risk in the development of coronary heart disease-six year follow-up experience. The Framingham Study. Ann Intern Med 1961; 55: 33-50

[47] Ettehad D, Emdin CA, Kiran A, Anderson SG, Callender T, Emberson J, Chalmers J, Rodgers A, Rahimi K. Blood pressure lowering for prevention of cardiovascular disease and death: a systematic review and meta-analysis. Lancet 2016; 387: 957-967

[48] Saxena T, Ali AO, Saxena M. Pathophysiology of essential hypertension: an update. Expert Rev Cardiovasc Ther 2018; 16: 879-887

[49] Higashi Y, Sasaki S, Nakagawa K, Matsuura H, Oshima T, Chayama K. Endothelial function and oxidative stress in renovascular hypertension. N Engl J Med 2002; 346: 1954-1962

[50] Maneesai P, Bunbupha S, Kukongviriyapan U, Senggunprai L, Kukongviriyapan V, Prachaney P, Pakdeechote P. Effect of asiatic acid on the Ang IIAT1R-NADPH oxidase-NF- $k B$ pathway in renovascular hypertensive rats. Naunyn Schmiedebergs Arch Pharmacol 2017; 390: 1073-1083

[51] Bunbupha S, Pakdeechote P, Kukongviriyapan U, Prachaney P, Kukongviriyapan $\mathrm{V}$. Asiatic acid reduces blood pressure by enhancing nitric oxide bioavailability with modulation of eNOS and p47phox expression in L-NAME-induced hypertensive rats. Phytother Res 2014; 28: 1506-1512

[52] Pakdeechote P, Bunbupha S, Kukongviriyapan U, Prachaney P, Khrisanapant W, Kukongviriyapan V. Asiatic acid alleviates hemodynamic and metabolic alterations via restoring eNOS/iNOS expression, oxidative stress, and inflammation in diet-induced metabolic syndrome rats. Nutrients 2014; 6: 355-370

[53] Maneesai P, Bunbupha S, Kukongviriyapan U, Prachaney P, Tangsucharit P, Kukongviriyapan V, Pakdeechote P. Asiatic acid attenuates renin-angiotensin system activation and improves vascular function in high-car- bohydrate, high-fat diet fed rats. BMC Complement Altern Med 2016; 16: 123

[54] Wang XB, Wang W, Zhu XC, Ye W], Cai H, Wu PL, Huang XY, Wang LX. The potential of asiaticoside for TGF- $\beta 1 /$ Smad signaling inhibition in prevention and progression of hypoxia-induced pulmonary hypertension. Life Sci 2015; 137: 56-64

[55] Wang X, Cai X, Wang W, Jin Y, Chen M, Huang X, Zhu X, Wang L. Effect of asiaticoside on endothelial cells in hypoxia-induced pulmonary hypertension. Mol Med Rep 2018; 17: 2893-2900

[56] Belcaro GV, Rulo A, Grimaldi R. Capillary filtration and ankle edema in patients with venous hypertension treated with TTFCA. Angiology 1990; 41: 12-18

[57] Belcaro GV, Grimaldi R, Guidi G. Improvement of capillary permeability in patients with venous hypertension after treatment with TTFCA. Angiology 1990; 41: 533-540

[58] Nelson RH. Hyperlipidemia as a risk factor for cardiovascular disease. Prim Care 2013; 40: 195-211

[59] Stancu CS, Toma L, Sima AV. Dual role of lipoproteins in endothelial cell dysfunction in atherosclerosis. Cell Tissue Res 2012; 349: 433-446

[60] Boulanger CM, Tanner FC, Bea ML, Hahn AW, Werner A, Luscher TF. Oxidized low density lipoproteins induce mRNA expression and release of endothelin from human and porcine endothelium. Circ Res 1992; 70: 1191-1197

[61] Estrada-Luna D, Ortiz-Rodriguez MA, Medina-Briseno L, Carreon-Torres E, Izquierdo-Vega JA, Sharma A, Cancino-Diaz JC, Perez-Mendez O, Belefant-Miller H, Betanzos-Cabrera G. Current therapies focused on high-density lipoproteins associated with cardiovascular disease. Molecules 2018; 23: 2730

[62] Anderson T], Gregoire J, Hegele RA, Couture P, Mancini GB, McPherson R, Francis GA, Poirier P, Lau DC, Grover S, Genest J jr., Carpentier AC, Dufour R, Gupta M, Ward R, Leiter LA, Lonn E, Ng DS, Pearson G], Yates GM, Stone JA, Ur E. 2012 update of the Canadian Cardiovascular Society guidelines for the diagnosis and treatment of dyslipidemia for the prevention of cardiovascular disease in the adult. Can I Cardiol 2013; 29: 151-167

[63] Kumari S, Deori M, Elancheran R, Kotoky J, Devi R. In vitro and in vivo antioxidant, anti-hyperlipidemic properties and chemical characterization of Centella asiatica (L.) extract. Front Pharmacol 2016; 7: 400

[64] Zhao Y, Shu P, Zhang Y, Lin L, Zhou H, Xu Z, Suo D, Xie A, Jin X. Effect of Centella asiatica on oxidative stress and lipid metabolism in hyperlipidemic animal models. Oxid Med Cell Longev 2014; 2014: 154295

[65] Oyenihi AB, Chegou NN, Oguntibeju OO, Masola B. Centella asiatica enhances hepatic antioxidant status and regulates hepatic inflammatory cytokines in type 2 diabetic rats. Pharm Biol 2017; 55: 1671-1678

[66] Gao L, Lin Z, Liu Y, Wang X, Wan L, Zhang L, Liu X. Hypolipidemic effect of Fragarianilgerrensis Schlecht. medicine compound on hyperlipidemic rats. Lipids Health Dis 2018; 17: 222

[67] Ramachandran V, Saravanan R, Senthilraja P. Antidiabetic and antihyperlipidemic activity of asiatic acid in diabetic rats, role of HMG CoA: in vivo and in silico approaches. Phytomedicine 2014; 21: 225-232

[68] Rameshreddy P, Uddandrao VVS, Brahmanaidu P, Vadivukkarasi S, Ravindarnaik R, Suresh P, Swapna K, Kalaivani A, Parvathi P, Tamilmani $P$, Saravanan G. Obesity-alleviating potential of asiatic acid and its effects on ACC1, UCP2, and CPT1 mRNA expression in high fat diet-induced obese Sprague-Dawley rats. Mol Cell Biochem 2018; 442: 143-154

[69] Larsson SC, Wallin A, Hakansson N, Stackelberg O, Back M, Wolk A. Type 1 and type 2 diabetes mellitus and incidence of seven cardiovascular diseases. Int J Cardiol 2018; 262: 66-70

[70] Nicholls S], Tuzcu EM, Kalidindi S, Wolski K, Moon KW, Sipahi I, Schoenhagen P, Nissen SE. Effect of diabetes on progression of coronary atherosclerosis and arterial remodeling: a pooled analysis of 5 intravascular ultrasound trials. J Am Coll Cardiol 2008; 52: 255-262 
[71] Low Wang CC, Hess CN, Hiatt WR, Goldfine AB. Clinical update: cardiovascular disease in diabetes mellitus: atherosclerotic cardiovascular disease and heart failure in type 2 diabetes mellitus - mechanisms, management, and clinical considerations. Circulation 2016; 133: 2459-2502

[72] Kabir AU, Samad MB, D'Costa NM, Akhter F, Ahmed A, Hannan JM. Antihyperglycemic activity of Centella asiatica is partly mediated by carbohydrase inhibition and glucose-fiber binding. BMC Complement Altern Med 2014; 14: 31

[73] Wang X, Lu Q, Yu DS, Chen YP, Shang J, Zhang LY, Sun HB, Liu J. Asiatic acid mitigates hyperglycemia and reduces islet fibrosis in Goto-Kakizaki rat, a spontaneous type 2 diabetic animal model. Chin J Nat Med 2015; 13: 529-534

[74] Chen YN, Wu CG, Shi BM, Qian K, Ding Y. The protective effect of asiatic acid on podocytes in the kidney of diabetic rats. Am J Transl Res 2018; 10: 3733-3741

[75] Ramachandran V, Saravanan R. Efficacy of asiatic acid, a pentacyclic triterpene on attenuating the key enzymes activities of carbohydrate metabolism in streptozotocin-induced diabetic rats. Phytomedicine 2013; 20: $230-236$

[76] Birben E, Sahiner UM, Sackesen C, Erzurum S, Kalayci O. Oxidative stress and antioxidant defense. World Allergy Organ J 2012; 5: 9-19

[77] Chen X, Andresen BT, Hill M, Zhang J, Booth F, Zhang C. Role of reactive oxygen species in tumor necrosis factor-alpha induced endothelial dysfunction. Curr Hypertens Rev 2008; 4: 245-255

[78] Dikalov S, Griendling KK, Harrison DG. Measurement of reactive oxygen species in cardiovascular studies. Hypertension 2007; 49: 717-727

[79] Gupta S, Prakash J. Studies on Indian green leafy vegetables for their antioxidant activity. Plant Foods Hum Nutr 2009; 64: 39-45

[80] Pittella F, Dutra RC, Junior DD, Lopes MT, Barbosa NR. Antioxidant and cytotoxic activities of Centella asiatica (L) Urb. Int J Mol Sci 2009; 10: 3713-3721

[81] Bajpai M, Pande A, Tewari SK, Prakash D. Phenolic contents and antioxidant activity of some food and medicinal plants. Int J Food Sci Nutr 2005; 56: 287-291

[82] Bian D, Liu M, Li Y, Xia Y, Gong Z, Dai Y. Madecassoside, a triterpenoid saponin isolated from Centella asiatica herbs, protects endothelial cells against oxidative stress. J Biochem Mol Toxicol 2012; 26: 399-406

[83] Arora R, Kumar R, Agarwal A, Reeta KH, Gupta YK. Comparison of three different extracts of Centella asiatica for anti-amnesic, antioxidant and anticholinergic activities: in vitro and in vivo study. Biomed Pharmacother 2018; 105: 1344-1352

[84] Golia E, Limongelli G, Natale F, Fimiani F, Maddaloni V, Pariggiano I, Bianchi R, Crisci M, D’Acierno L, Giordano R, Di Palma G, Conte M, Golino P, Russo MG, Calabro R, Calabro P. Inflammation and cardiovascular disease: from pathogenesis to therapeutic target. Curr Atheroscler Rep 2014; 16: 435

[85] Molteni M, Gemma S, Rossetti C. The role of toll-like receptor 4 in infectious and noninfectious inflammation. Mediators Inflamm 2016; 2016: 6978936

[86] George M, Joseph L, Ramaswamy. Anti-allergic, anti-pruritic, and anti-inflammatory activities of Centella asiatica extracts. Afr J Tradit Complement Altern Med 2009; 6: 554-559

[87] Saha S, Guria T, Singha T, Maity TK. Evaluation of analgesic and anti-inflammatory activity of chloroform and methanol extracts of Centella asiatica Linn. ISRN Pharmacol 2013; 2013: 789613

[88] Huang SS, Chiu CS, Chen HJ, Hou WC, Sheu MJ, Lin YC, Shie PH, Huang G]. Antinociceptive activities and the mechanisms of anti-inflammation of asiatic acid in mice. Evid Based Complement Alternat Med 2011; 2011: 895857

[89] Yang C, Guo Y, Huang TS, Zhao J, Huang XJ, Tang HX, An N, Pan Q, Xu YZ, Liu HF. Asiatic acid protects against cisplatin-induced acute kidney injury via anti-apoptosis and anti-inflammation. Biomed Pharmacother 2018; 107: 1354-1362
[90] Branen L, Hovgaard L, Nitulescu M, Bengtsson E, Nilsson J, Jovinge S. Inhibition of tumor necrosis factor-alpha reduces atherosclerosis in apolipoprotein E knockout mice. Arterioscler Thromb Vasc Biol 2004; 24: 2137-2142

[91] Tay C, Liu YH, Hosseini H, Kanellakis P, Cao A, Peter K, Tipping P, Bobik A, Toh BH, Kyaw T. B-cell-specific depletion of tumour necrosis factor alpha inhibits atherosclerosis development and plaque vulnerability to rupture by reducing cell death and inflammation. Cardiovasc Res 2016; 111: 385-397

[92] Ohta H, Wada H, Niwa T, Kirii H, Iwamoto N, Fujii H, Saito K, Sekikawa $K$, Seishima M. Disruption of tumor necrosis factor- $\alpha$ gene diminishes the development of atherosclerosis in ApoE-deficient mice. Atherosclerosis 2005; 180: 11-17

[93] Boesten LS, Zadelaar AS, van Nieuwkoop A, Gijbels MJ, de Winther MP, Havekes LM, van Vlijmen BJ. Tumor necrosis factor- $\alpha$ promotes atherosclerotic lesion progression in $\mathrm{APOE}^{*} 3$-Leiden transgenic mice. Cardiovasc Res 2005; 66: 179-185

[94] Jeng JR, Chang CH, Shieh SM, Chiu HC. Oxidized low-density lipoprotein enhances monocyte-endothelial cell binding against shear-stressinduced detachment. Biochim Biophys Acta 1993; 1178: 221-227

[95] Pirillo A, Norata GD, Catapano AL. LOX-1, OxLDL, and atherosclerosis. Mediators Inflamm 2013; 2013: 152786

[96] Guo F, Zhou Z, Dou Y, Tang J, Gao C, Huan J. GEF-H1/RhoA signalling pathway mediates lipopolysaccharide-induced intercellular adhesion molecular-1 expression in endothelial cells via activation of p38 and NF- $\kappa$ B. Cytokine 2012; 57: 417-428

[97] Di Tomo P, Di Silvestre S, Cordone VG, Giardinelli A, Faricelli B, Pipino C, Lanuti P, Peng T, Formoso G, Yang D, Arduini A, Chiarelli F, Pandolfi A, Di Pietro N. Centella asiatica and lipoic acid, or a combination thereof, inhibit monocyte adhesion to endothelial cells from umbilical cords of gestational diabetic women. Nutr Metab Cardiovasc Dis 2015; 25 : 659-666

[98] Fong LY, Ng CT, Zakaria ZA, Baharuldin MT, Arifah AK, Hakim MN Zuraini A. Asiaticoside inhibits TNF- $\alpha$-induced endothelial hyperpermeability of human aortic endothelial cells. Phytother Res 2015; 29: $1501-1508$

[99] Fong LY, Ng CT, Cheok ZL, Mohd Moklas MA, Hakim MN, Ahmad Z. Barrier protective effect of asiatic acid in TNF- $\alpha$-induced activation of human aortic endothelial cells. Phytomedicine 2016; 23: 191-199

[100] Fong LY, Ng CT, Yong YK, Hakim MN, Ahmad Z. Asiatic acid stabilizes cytoskeletal proteins and prevents TNF- $\alpha$-induced disorganization of cell-cell junctions in human aortic endothelial cells. Vascul Pharmacol 2019; 117: 15-26

[101] Jing L, Haitao W, Qiong W, Fu Z, Nan Z, Xuezheng Z. Anti inflammatory effect of asiaticoside on human umbilical vein endothelial cells induced by ox-LDL. Cytotechnology 2018; 70: 855-864

[102] Nhiem NX, Tai BH, Quang TH, Kiem PV, Minh CV, Nam NH, Kim JH, Im LR, Lee YM, Kim YH. A new ursane-type triterpenoid glycoside from Centella asiatica leaves modulates the production of nitric oxide and secretion of TNF- $\alpha$ in activated RAW 264.7 cells. Bioorg Med Chem Lett 2011; 21: 1777-1781

[103] Yun KJ, Kim JY, Kim JB, Lee KW, Jeong SY, Park HJ, Jung HJ, Cho YW, Yun $\mathrm{K}$, Lee KT. Inhibition of LPS-induced NO and PGE2 production by asiatic acid via NF-KB inactivation in RAW 264.7 macrophages: Possible involvement of the IKK and MAPK pathways. Int Immunopharmacol 2008; 8: 431-441

[104] Won JH, Shin JS, Park HJ, Jung HJ, Koh DJ, Jo BG, Lee JY, Yun K, Lee KT. Anti-inflammatory effects of madecassic acid via the suppression of NF-kappaB pathway in LPS-induced RAW 264.7 macrophage cells. Planta Med 2010; 76: 251-257 